Divers@ Revista Eletrônica Interdisciplinar,

Matinhos, v. 14, n. 1, p. 4-15, jan./jun. 2021

ISSN 1983-8921

doi: http://dx.doi.org/10.5380/diver.v14i1.76114

\title{
DIVERS@!
}

\section{PROPOSIÇÕES SOBRE A FORMAÇÃO INICIAL DE PROFESSORES*}

\author{
PROPOSALS ON INITIAL TEACHER TRAINING
}

João Pedro Goes Lopes ${ }^{1}$

\begin{abstract}
Resumo
O presente artigo objetiva firmar posição sobre a formação inicial de professores, dialogando com proposições para o campo. Para tanto, apoia-se, principalmente, no campo teórico dos Estudos Culturais e fundamenta suas articulações a partir do conceito de cultura - com base nos escritos de Stuart Hall, para quem a cultura é traduzida em produções de significados que nunca se estabelecem sem um campo de luta. Apoiados em seis proposições, transitamos entre a formação em seu formato institucionalizado, sobre suas políticas e a produção da identidade docente promovida por essa formação. São elas: (1) a discussão em relação a profissão docente ser invariavelmente política; (2) a atenção à história da formação docente como possibilidade de continuidade do que já foi produzido e conquistado; (3) a formação para além dos espaços da própria formação inicial de professores; (4) a necessidade do permanente questionamento sobre o papel docente e sua identidade como forma de atuação crítica; (5) a urgência da ocupação de espaços pelos docentes como forma de firmar posições; (6) e, por fim, a argumentação de que universidade e escola precisam ser dois lados da mesma moeda. O principal intento é demonstrar a plasticidade da cultura e, por meio da perspectiva da multiplicidade, produzir resistência às representações que detratam a profissão docente e, atualmente, por meio de um discurso poderoso, o ensino superior, principalmente de caráter público.
\end{abstract}

Palavras-chave: Formação de professores; Estudos culturais; Cultura; Identidade docente.

\begin{abstract}
This article aims to establish a position on the initial training of teachers, dialogizing with proposals for the field. To this end, it relies mainly on the theoretical field of Cultural Studies and bases its articulations on the concept of culture - based on the writings of Stuart Hall, for whom culture is translated into productions of meanings that are never established without a fighting field. Supported by six propositions, we move between training in its institutionalized format, its policies, and the production of the teaching identity promoted by this training. They are: (1) the discussion regarding the teaching profession is invariably political; (2) attention to the history of teacher education as a possibility of continuing what has already been produced and achieved; (3) training beyond the spaces of the initial teacher training itself; (4) the need for permanent questioning about the teaching role and its identity as a form of critical
\end{abstract}

* Artigo Original: Recebido em 27/08/2020 - Aprovado em 28/10/2020.

${ }^{1}$ Graduado em Educação Física, Especialista em Educação Física Escolar e Mestre em Educação. Professor da rede SESI/SP (Serviço Social da Indústria de São Paulo), Boituva/SP, Brasil. Membro do Grupo de Pesquisas em Pedagogia da Educação Física da FEFISO (GEPEF), do Núcleo de Estudos e Pesquisas sobre Narrativas Educativas, Formação e Trabalho Docente da UFSCar - Sorocaba (NEPEN) e do Grupo Transgressão da UNICAMP (GT).e-mail: joaopgoes@hotmail.com ORCID: https:// orcid.org/0000-0002-4415-7603 (autor correspondente)

Apoio financeiro: Coordenação de Aperfeiçoamento de Pessoal de Nivel Superior 
action; (5) the urgency of the occupation of spaces by teachers as a way of establishing positions; (6) and, finally, the argument that university and school need to be two sides of the same coin. The main aim is to demonstrate the plasticity of culture and, through the perspective of multiplicity, to produce resistance to the representations that detract from the teaching profession and, currently, through a powerful discourse, higher education, mainly of a public character.

Keywords: Teacher training; Cultural studies; Culture; Teaching identity.

\section{Introdução}

Acompanhamos diversas discussões a respeito da formação inicial de professores. Exemplo disso são os debates acalorados sobre as universidades (em geral, públicas) e o questionamento sobre o tipo de formação que oferecem - que, como consequência, formaria um tipo de ideologia nefasta que se espalharia pelo tecido social com o objetivo do domínio cultural; em outros casos, a concentração está voltada para o destino ou não das verbas que são juridicamente asseguradas às instituições e que, por efeito, atingem também a formação de professores para a educação básica, colocando em xeque sua necessidade e organização.

É também bastante comum que nos encontremos (as vezes até despretensiosamente) alocados em um debate acirrado sobre a caracterização das instituições de ensino superior: devem ser gratuitas? São de responsabilidade do Estado? Se estão em condições precárias, formam, em tese, professores(as) pouco preparados para o ofício, o que gera insatisfação e demanda pela privatização desses espaços de educação. Ao mesmo tempo, passa a ser preocupante o destaque de instituições de ensino superior privadas que se responsabilizam pela formação dos(as) futuros professores, e que, como aponta Zeichner (2013), entendem a formação enquanto nicho de mercado e seu crescimento exageradamente maior do que das instituições públicas.

É nesse sentido que a ampliação do Ensino a Distância $(\mathrm{EaD})$ também se torna uma importante questão: o futuro da formação de professores será em cursos de ensino remoto? Como formar professores(as) que tiveram o contato com alunos(as) e outros(as) professores(as) amplamente reduzidos por modalidades à distância?

São amplos os questionamentos e precisaríamos, certamente, do espaço de um artigo inteiro para problematizar as relações contemporâneas da sociedade globalizada e as atuais demandas (positivas ou não) sobre a formação inicial de professores(as). Far-se-á outro o objetivo desse artigo: em meio a tantos questionamentos, intentamos lançar mão de possíveis proposições para o campoi. Sabemos, então, que muitas são as dúvidas que nos acometem e ainda mais as críticas que são direcionadas à formação - por vezes, até por parte dos(as) seus/suas próprios(as) profissionais.

Em última instância, propor aquilo que gira em torno das nossas próprias discussões, daquilo que parece, para nossos debates e atuação, importante de ser focalizado. É nesse sentido que queremos intitular o artigo (e chamar a atenção) para o seu caráter transitório e (insistentemente) propositivo, que se reconhece enquanto mais uma possibilidade, dentre outras possíveis - não sendo, por isso, fundamental ou imprescindível.

Não pretendemos, então, esgotar as questões referentes ao assunto, o esforço dar-se-á com o objetivo de intervir culturalmente na área. Segundo Hall (1997) chamamos de cultura todos esses processos que envolvem a produção dos significados compartilhados em determinado contexto - que são essencialmente conflitantes dentro das relações da linguagem, meio pelo qual ela é produzida. É ainda segundo o pensador que devemos afirmar que qualquer tipo de mudança cultural não corresponde à causa-efeito da ação em relação a um objeto, a uma instituição ou a um ator em específico, mas que:

aqueles que precisam ou desejam influenciar o que ocorre no mundo ou o modo como as coisas são feitas necessitarão - a grosso modo - de alguma forma ter a "cultura" em suas mãos, para moldá-la e regulá-la de algum modo ou em certo grau (HALL, 1997, p. 40).

Podemos inferir, pelo menos, duas assertivas: a primeira está relacionada ao fato de que a cultura, concebida enquanto compartilhamento de 
significados produzidos, medeia todas as nossas relações sociais e transpassa toda a nossa concepção de realidade (inclusive, aquilo que pensamos sobre a formação inicial de professores(as), ou, além, a maneira como formamos nossos(as) professores(as). Em segundo lugar que, então, logicamente, as frentes de pensamento em relação às culturas que envolvem a formação de professores(as) não poderiam corresponder à uma ponta isolada do triângulo "profissão", "formação inicial de professores" e "políticas públicas", mas devem, ao contrário, todas essas estarem em constante relação. Podem certamente receber um maior destaque em determinada conjuntura social, no entanto, não podem jamais apresentar intervenções atomizadas ${ }^{\mathrm{ii}}$, como propõem Guattari e Rolnik (2010).

Pensamos que a discussão que propomos pode moldar e regular a cultura com o intuito de resistir à rebaixamentos e aos ataques sofridos pela educação, pela formação e pelas instituições (principalmente de caráter público, como comentado). Dessa forma, é preciso que façamos essa ressalva, pois, como mostra Hall (1997), as questões não devem girar em torno do binarismo emancipação e controle, pois "não se trata de uma opção entre liberdade e restrição, mas entre modos diferentes de regulação" (p. 37, grifos do autor). Ou seja, em outras palavras, propor intervenções na maneira como a cultura é produzida, não nos faz arautos do pensamento emancipatório, pois é, no máximo, uma linha de frente composta por novas significações da realidade que de uma maneira ou de outra, fixará como proposta a regulação cultural. O que queremos dizer é isso: não trataremos aqui de libertar a formação de professores de um pensamento regulador (com seus efeitos positivos e/ou negativos); mas de aguçar novas regulações que moldem a cultura em uma perspectiva potencializadora à ação da formação de professores.

É dessa forma que nos debruçamos a pensar em seis proposições sobre a formação inicial de professores, no intuito de que elas possam construir resistência às representações que em nada contribuem para a composição com o campo, mas que produzem antagonismos à área, produzindo uma cultura de precarização à educação pública, à argumentação irreal sobre a sua falta de necessidade e, mais grave, o ataque direto à profissão docente. Levantamo-nos em favor da contra-argumentação demonstrando que se a construção de uma identidade social negativa da formação de professores e da própria profissão docente se faz possível, é certo que novas identidades culturais podem ser promovidas em relação ao mesmo campo tomando como ponto de partida a noção de que os sentidos podem ser, sempre, negociados, e produzidos novamente. Dessa forma, não argumentaremos para que um novo lugar definitivo seja criado; mas argumentaremos em prol das múltiplas produções resistentes, que afirmem a posição docente (NÓVOA, 2017) enquanto um trabalho sério, responsável e compromissado com a vida pública.

\section{Proposições sobre a formação inicial de professores(as)}

\subsection{A profissão docente é política}

A primeira proposição segue a seguinte argumentação: como vimos, a profissão docente é, inevitavelmente, política. Nesse sentido, é preciso que reconheçamos não só a necessidade de um posicionamento frente aos movimentos sociais, mas que, para além disso, entendamos a impossibilidade de esquiva do debate político: o(a) professor(a) é um(a) dos(as) agentes que mais se relaciona com a pólis do contexto cultural em que vive - o que não afirma, claro, que haja envolvimento engajado com a vida pública desse mesmo espaço.

Em outro momento, aprendemos com Silva (2017) que o currículo, entendido enquanto espaço-tempo de negociação cultural (MACEDO, 2006), nunca é neutro: "Nas teorias de currículo, entretanto, a pergunta "o quê" nunca está separada de outra importante pergunta: "o que eles ou elas devem ser?" ou, melhor, "o que eles ou elas devem se tornar?" (SILVA, 2017, p. 15). Queremos com isso atentar à própria dinâmica curricular: nem a formação inicial de professores(as) e muito menos a escola preveem currículo despolitizados, porque o currículo demarca sempre uma espacialidade, uma intenção.

Assim, ao formarmos professores(as), que formarão novos(as) alunos(as) e novos(as) professores(as), que se perguntam e respondem sobre "o que meus/minhas alunos(as) devem se tornar?" ou "como/onde/por que devem aprender ou chegar em determinado lugar?", formamos pessoas a partir de currículos específicos e, por isso mesmo, formamos professores(as) em contextos políticos específicos. Nesse sentido, resguardadas as limitações teóricas que podemos incorrer, Silva (2017) indica três possibilidades 
curriculares, mas que, aqui, entenderemos também enquanto posturas éticas: tradicionalismo, criticismo e pós-criticismo.

A primeira, abertamente conteudista, reprodutivista, foca seus esforços na conquista de objetivos já pré-determinados de antemão e costuma demonstrar sua eficácia através de exames padronizados que atestam a objetividade de seus intuitos - diz-se que seus sujeitos (professores(as), alunos(as)) formam-se preparados para dar continuidade aos sistemas opressivos e desiguais instaurados na sociedade mais ampla. Já o segundo e o último, respeitando suas singularidades teóricas que nos interessam pouco nesse momento, lançam olhares críticos à composição social e preferem desconfiar dos arranjos que foram construídos. Afirma-se que seus sujeitos estão constantemente preocupados com os rumos mais amplos de suas aulas e que são capazes de examinar a realidade a partir de uma ótica menos rígida (SILVA, 2017).

O que se intenta argumentar com esse debate é que mesmo uma formação de professores pouco preocupada com uma visão crítica sobre os encaminhamentos sociais, que se interesse, de outra maneira, mais pelas questões que envolvam o capital e a sobrevivência no mercado, forma politicamente seus/suas professores(as) dentro de uma visão tradicionalista de docência, de escola e de partícipes do processo educativo. Se a própria formação não puder duvidar da realidade da educação, não puder jogar com seus significados com o objetivo de produzir tantos outros quanto necessário, como cobrar que seus/suas professores(as) hajam, eticamente, diferente disso? Ora, é preciso que assumamos nossa posição política sem maiores amarras - pois, com isso, trabalharemos fundamentalmente com concepções (também políticas) que abominem a função-professor(a) como a função do replicador(a), do expositor(a) ou do(a) avaliador(a), o que nos remete à um outro espaço cultural de construção da identidade docente.

Por outro lado, é preciso que fique claro: firmar a posição política da formação de professores(as) e da docência não prevê, necessariamente, a afirmação partidária dos indivíduos atuantes. Não há, claramente, nenhuma objeção em relação a isso, inclusive, coadunamos com a interpretação de que é algo positivo em relação à responsabilidade com o coletivo. No entanto, o sentido de política aqui advém do seu trato com o social, de maneira mais ampla, de sua relação com a pólis, e com seus/suas cidadãos(ãs) e indivíduos. Reconhecer sua posição política é reconhecer, necessariamente, que o docente (e a formação responsável) é sujeito em relação com outros(as) e que suas ações desencadeiam efeitos para além dos contornos de sua própria materialidade. Chamamos de política essa relação que prevê a necessária conexão da cultura em suas diferentes instâncias, que por isso mesmo distribui o peso de uma responsabilidade ainda maior para a formação inicial de professores(as).

É justamente por isso que o conceito de identidade nessa perspectiva (HALL, 2006; 2014; WOODWARD, 2014) não pode jamais corresponder a um objeto de estudo de um interior subjetivo inexplorado pelos "outros". A identidade é produzida socialmente, o que corresponde mais a possibilidade de posicionamento dos(as) sujeitos nos discursos circulantes em determinadas culturas, do que da descoberta de um suposto "si mesmo". A formação inicial precisa garantir (lutar e contribuir para) a construção de uma identidade social docente política. Assim, para que potencializemos a inserção dos indivíduos em uma cultura que promova uma identidade docente engajada com o debate público mais amplo, podemos discutir nas formações com mais profundidade a segunda proposta que trata, justamente, sobre a construção da própria profissão, muito atrelada às políticas públicas que versam sobre a docência.

\subsection{História como possibilidade de continuidade}

Entendemos que um ponto importante da formação inicial de professores se dá em relação à história da própria profissão docente relativa a qualquer área e à docência de forma geral. No entanto, não apenas pela necessidade de conhecer os eventos passados, por saudosismo, ou amor ao pensamento sedentário (SCHÉRER, 2005), mas por aquilo que estamos chamando de "possibilidade de continuidade". Defendemos que o trabalho insistente sobre a história da profissão pode - além de potencializar a produção de uma identidade social alternativa, como comentado na proposição anterior - contribuir rivalizando com uma demanda muito importante da profissão docente: a descontinuidade das políticas públicas.

Gatti et al. (2019), em produção recente, articula de várias maneiras o pensamento histórico e atual, 
comentando sobre diferentes tipos de políticas propostas e trabalhos desenvolvidos. Algo, no entanto, que chama a atenção, é a descontinuidade das políticas públicas realizadas e dos programas propostos. Muitas propostas postas em prática, mesmo que tenham representado avanços ou apresentado bons resultados do ponto de vista daqueles(as) envolvidos(as), são submetidas a processos de desmantelamento, a corte de verbas, ou encerramentos, simplesmente, na troca de governos mandatários municipais, estaduais ou federais.

Permitam-nos jogar com o conceito de "continuidade", negociar suas possibilidades de significação. Não advogamos por uma continuidade histórica, é Foucault (2008) quem desmonta essa ideia quando propõe que a história precisa ser vista, contemporaneamente, como a "história das rupturas" ou das "irrupções" - no sentido de que não há, realmente, continuidade histórica bem definida e muito menos sujeitos capazes de ditar (e entender) o seu ritmo enquanto um movimento linear; o que existem são rupturas e o arqueólogo é aquele quem estudará as condições de emergência de determinados discursos em determinados tempos históricos (como, por exemplo, quando a medicina pôde "falar" sobre a loucura e, dessa forma, produzir o louco). Claro, não se faz esse o objetivo do artigo, no momento. O que queremos dizer é que a questão não está na possibilidade de novas irrupções sobre a profissão docente, sobre a formação de professores ou sobre as políticas públicas de qualquer espaço possível: nosso argumento se insurge contra o constante recomeço das histórias. Sem um trabalho aprofundado, atentamos para o fato de que esse tipo de postura não permite trabalhos a longo prazo, o que é exigência de um pensamento educacional.

Um trabalho inicial de formação que atente a essas problemáticas, parece-nos, será um forte aliado nas transformações necessárias a essas questões, pois pode, ao menos, demonstrar a circularidade de muitas "novidades" atuais, assim como o histórico de lutas já traçados pela afirmação da profissão docente. Isso quer dizer, de maneira velada, que a responsabilidade é somente dos(as) professores(as) formadores(as) e em formação? De forma alguma! No entanto, retomemos a discussão sobre a atomização cultural: não se pode pensar em termos de políticas públicas ou formação ou atuação profissional. O pensamento rigoroso precisa atentar-se à multiplicidade das perspectivas
(DELEUZE, 2018): pensemos em termos de políticas públicas $e$ formação $e$ atuação profissional.

Demonstramos anteriormente que a produção de uma identidade docente engajada politicamente é fator importante para a potencialização da atuação em relação aos destinos da comunidade social. Certamente que os espaços de atuação são inúmeros e não caberia a nós a instituição dos fundamentos atuantes de cada ator social ou contexto cultural. Queremos somente reforçar, como já fizeram tantos outros trabalhos nesse mesmo sentido, a interdependência dos processos - não porque precisamos que eles tenham relação; mas porque suas relações são sempre inevitáveis. Cabe a nós, nesta oportunidade, focar mais na atuação docente.

É de um pensamento relacional que advém a terceira proposta desse artigo, um importante questionamento: como pensar a formação para além dela?

\subsection{Formação para além da formação inicial de professores}

Chamemos de híbrido aquilo que acima chamamos de relacional. É necessário fundamentar. Baseados em Garcia Canclíni (2019) reconheceremos o movimento fundamentalmente híbrido da cultura. Com Hall (1997) pressupusemos que a cultura é, basicamente, a produção de sentidos compartilhados. Seria, da mesma forma, simplista demais pressupor que esses significados são, apenas, compartilhados. A cultura é, como afirmou Silva (2017), uma arena de confrontos. Isso quer dizer que os sentidos não são simplesmente produzidos e compartilhados, mas estão a todo momento disputando espaço de ocupação - uma espécie de conatus da linguagem, uma insistência na própria existência. Isso ocorre porque a linguagem possui uma característica profundamente "diferencial", ou seja, quando "algo" se torna "algo" - é significado - só pode ser esse algo porque não é muitos outros "algos". Silva (2014), exemplifica essa relação: ser "brasileiro" é não ser de qualquer outro país. Ser "brasileiro" é um artifício linguístico mais econômico do que negar todas as outras possíveis nacionalidades.

Aqui se dá um nó importante sobre a hibridez cultural: não há descoberta do significado que esteve sempre ali; ao contrário, se o que há são disputas de espaços, poder de representação e de significação, 
então não existem práticas, entendimentos, formações, com fundamentações "puras". Se não existem formações puras, não há lugar fundamental de chegada ou saída - ou seja, podemos entender a cultura em sua característica de produção múltipla, e não dialética. Que isso quer dizer?

Pelo menos dois pontos fundamentais são levantados em relação a isso: tratando-se de formação inicial de professores(as) não há resultado essencialmente seguro a se pautar - e isso, arriscaríamos, é basilar de uma perspectiva dita pós-crítica; assim como não há espaço e momento específico em que ocorra a formação (seja o prédio da instituição que oferece a graduação ou as salas em que se oferece a formação continuada) - o que implica, numa perspectiva como essa, ser equivocado pensar que é a formação quem forma professores(as).

Algumas palavras sobre a primeira afirmação. Queremos, em suma, perguntar (retoricamente): quem de nós afirmará a verdade sobre o que é ser professor(a)? Sobre como lidar com os(as) alunos(as)? Quem de nós, cientificamente, provará o que deve ser feito na escola do centro e na escola rural? A grande questão não está, logicamente, na recusa em relação a qualquer tipo de estudo que já tenha sido feito na educação, mas em reforçar, por outro lado, que nenhum conteúdo formativo poderá dar conta da multiplicidade dos jogos da linguagem e, por isso, da cultura - já que é, ela própria, resultado de infinitas possibilidades híbridas que os jogos de força produzem em relação ao estanque dos significados. Compreender a formação como espaço privilegiado da produção do saber científico (e por isso mais válido), é parte importante da conservação do grande distanciamento que se vê em relação à universidade e a escola.

$\mathrm{Na}$ verdade, o problema é ainda mais simples: não é que cada espaço possui a sua cultura própria; ao contrário, cada espaço corresponde, de diversas maneiras, ao devir múltiplo da cultura. É dessa forma que métodos precisarão ser negociados; concepções precisarão ser reformuladas; acordos necessitarão acontecer; dentre outras coisas. Em outras palavras, cada atuação do(a) recém formado(a) ou do(a) professor(a) mais antigo(a) será traduzida à sua maneira. Como a formação deveria se pautar frente a isso? Não temos o intento de desenvolver questões tão complexas nesse espaço limitado de escrita, mas poderíamos dizer que é com isso em mente que precisaríamos fazer um primeiro avanço da formação sobre a própria formação: não só não existem resultados seguros que possamos nos pautar, mas seria necessário, o quanto antes, pensar a formação para além da sala de aula - não só com o estágio ou horas complementares, mas como uma postura ética frente à realidade.

Isso nos traz ao segundo ponto: não há espaço de formação. A formação aqui é, poderíamos dizer, espaço privilegiado para as negociações que constituem os sentidos sobre ser professor(a), sobre identidade docente, sobre escola, educação, e tantos outros; poderíamos falar, talvez, em espaços formativos que potencialmente constituem parte de uma formação que é, fatalmente, fragmentada - não no sentido depreciativo do termo, mas ao estilo que Hall (2006) desenvolve para pensar a identidade na sociedade contemporânea. Avançando mais uma vez a formação sobre a própria formação, poderíamos arriscar dizer: a formação ocorre em todos os espaços, é negociada e transformada em todos os espaços. Diríamos que a riqueza da formação inicial de professores(as) não está alocada no domínio instrumental, metodológico e científico sobre o que é ser professor(a); mas na variabilidade de espaços que medeia para a construção da identidade docente. Potencialmente, como propõe Deleuze (2018), qualquer força pode produzir novas interpretações das significações - no nosso caso, de determinadas significações de contextos culturais.

A transformação de qualquer domínio instrumental não é, para nós, uma opção, mas uma necessidade. Estamos convencidos de que uma formação não é, necessariamente, falha por possuir características tecnicistas; mas é prontamente balizada naquilo que pode quando restrita ao espaço único da formação. É nesse sentido que a formação de professores(as), pensamos, precisa ser encarada para além dela mesma - não há metáforas aí. Alguns estudos como o de Zeichner (2013) e Nóvoa (2017) apontam para aquilo que chamam de "formação híbrida" ou "espaços híbridos na formação". Guardadas as diferenças em relação ao híbrido que utilizamos neste artigo, os autores parecem apontar para um consenso (por mais tradicional que seja) de que a formação não pode estar restrita a ela mesma, mas necessita "fronteirizar" com espaços diversos que, no caso dos dois estudos, refere-se à educação básica e a comunidade.

Por outro lado, antes das definições, precisaríamos nos atentar ao que Zeichner (2013, p. 227) escreve: 
"Do nosso ponto de vista, o mais importante e necessário é uma mudança fundamental naquilo que conta como conhecimento na formação de novos professores e no trabalho de formadores de professores das faculdades e universidades". Essa passagem, ao nosso ver, é de caráter indispensável pois se comunica tanto com o primeiro quanto com o segundo desdobramento dessa terceira proposição para a formação inicial de professores. Levemos a sério a provocação, tenhamos a liberdade de reformular constantemente nossas convicções sobre a formação; da mesma maneira que a(s) cultura(s) é(são) capaz(es) de se desdobrar em múltiplas possibilidades, proliferando diversas significações sobre a(s) realidade(s) - não se trata de relativismo; mas, por outro lado, de reconhecer que "o múltiplo é a manifestação inseparável, a metamorfose essencial, o sintoma constante do único" (DELEUZE, 2018, p.37). E é esse tipo de questionamento que nos direciona para a quarta proposição.

\subsection{Precisamos questionar continuamente sobre o papel do(a) professor (a) e sobre sua identidade}

Seria necessário, antes, questionar: de que identidade falamos? O que seria questioná-la? Voltemos a já anunciada interlocução com Stuart Hall, para quem a identidade possui dois níveis intrinsecamente conectados - o social e o subjetivo (HALL, 2006; 2014). Quando o pensador fala sobre identidade, refere-se à possibilidade de sua construção social, cultural, que, nesse sentido, diz respeito a determinadas posições de sujeito, produzidas pelos discursos, que "nos chamam" a assumir determinado posicionamento (como, por exemplo, a identidade social de professor(a).

Todos os questionamentos e possíveis respostas sobre o que é ser professor(a) estão contidos nessas diferentes identidades produzidas na/pela cultura); por outro lado, também trata da identidade enquanto uma questão subjetiva, do próprio sujeito, ou, em outras palavras - que me perdoem a simplificação "o que leva alguém a se identificar com determinada posição de sujeito?" (e a isso poderíamos dizer que corresponde ao fato de alguém afirmar "Eu sou professor(a)!”, “Sempre quis ser professor(a)!", "Tenho orgulho de ser professora(a)", dentre tantas outras afirmações que costumeiramente ouvimos falar e, por que não, também com elas nos expressamos). Isso quer dizer que o problema se dá tanto em nível social (onde Hall (2006) busca explicações na sociologia), como em nível subjetivo (quando Hall (2014) busca apoio em Michel Foucault e na psicanálise, com Sigmunt Freud, Jacques Lacan, entre outros). Para fins desse artigo (e por outras ressalvas), focaremos mais especificamente a identidade social do(a) professor(a), ou como podemos nos referir também, a identidade cultural dos(as) professores(as).

Ora, contudo, em que medida isso se encaixa na formação inicial de professores? Deter-nos-emos numa em específico: qualquer tipo de identidade docente é sempre uma construção social-cultural, o que indica, em outras palavras, como anunciamos no início do artigo, que suas múltiplas construções (e conexões) podem ocorrer da maneira como houver necessidade. Frisamos o conceito de "conexão" já que, para Hall (2006), trata-se de uma ideia de identidade "pós-moderna" (que é essencialmente fragmentada), diferente da identidade-iluminista ou identidade-sociológica, que guardam resquícios modernos de completude e essencialidade. A identidade pós-moderna não cansa de se fragmentar e nem de produzir novas possibilidades no encontro com novos discursos, seu caráter é insistentemente híbrido. Não se busca, dessa forma, a análise do todo (ou o próprio todo), interessa mais saber a que jogos de força são submetidas as identidades e quais fragmentos, de quais discursos, contextos, espaços culturais, passam a compor essas "posições de sujeito" (ou "posições de professores(as)"). O que isso sugere também é que podemos transitar entre a multiplicidade e que podemos, por que não, intervir culturalmente na criação de novas identidades, novas posições das quais os sujeitos podem "se identificar" (ou desejar ${ }^{\mathrm{iii}}$ ).

Sumariamente: se não há essencialidade no debate sobre a identidade e atribui-se sua produção a diferentes convenções sociais, essas podem ser desconstruídas e traduzidas pelos(as) professores(as) das mais diversas formas. É nesse nó que chamamos a atenção para a importância dessa quarta proposição: a formação inicial, questionando a identidade cultural da profissão docente, precisa ter o compromisso de não balizar, novamente, aquilo que pode o professor; mas, por outro lado, precisa cuidar para que suas potencialidades estejam sempre aparentes. Nossa 
proposta, apoiados nessa perspectiva, é, então, de um duplo compromisso.

Por um lado, a constante vigilância do pensamento crítico sobre a identidade social do(a) professor(a): quem é o(a) professor? O que ele(a) faz e como age? Assim, vemos a possibilidade de contraconduta frente a tudo aquilo que subjuga a profissão - vêse que é muito mais fácil questionar aquilo que se sabe não possuir fundamento inquestionável. Parece simples, mas as articulações corriqueiras desse pensamento não são de maneira nenhuma óbvias. Por outro, o exercício do pensamento ativo, culturalmente orientado para os novos problemas (infindáveis) que surgem com a docência, com as escolas, com os(as) alunos - problemas que exigem novas criações, posições e posturas: novas conexões. É focando a cultura que poderemos questionar os problemas colocados como fundamentais para a formação inicial - lembremos que eles podem ser radicalmente diferentes.

Isso implica, novamente, em todas as outras propostas: novos posicionamentos políticos que enxergam sujeitos-alunos(as) e sujeitosprofessores(as) como politicamente orientados nos contextos sociais - não há "identidade neutra", pois correspondem, todas, a jogos de poder; o forte trabalho sobre a história para que demonstrem-se as disposições das culturas e a construção temporal/ contextual das diferentes representações dos(as) professores(as) e proposições sobre a profissão docente; da mesma forma como o entendimento de que a formação da identidade dos(as) professores(as) não se dá em sala de aula, na formação, mas para além dela, em todos os significados propostos pela cultura.

Logo, a grande questão que se tem, ou que se busca produzir, é que a formação inicial, ao tratar da política, da história, ou da identidade da profissão docente, precisa estar descentrada, como é a característica da própria cultura. Os espaços formativos são os mais variados e, nesse sentido, pensar em algo como "formação inicial" também precisa ser questionado. Por enquanto, utilizemos o conceito "sob rasura" (HALL, 2014) e debatamos a quinta proposta sobre a formação inicial de professores(as) que, nessa linha, poderíamos dizer, possui forte relação com a ideia de espaços descentrados.
2.5 Professores precisam ocupar espaços, firmar posições

Nóvoa (2017) desenvolve uma ideia bastante profícua em relação ao "posicionamento" disposição, interposição, composição, recomposição e exposição. Nossa proposta é, por outro lado, inspirada em vias da própria cultura - nem pior, nem melhor, mas, certamente, com um tom diferente. Os espaços aqui são os espaços das negociações; das representações; das políticas; dos embates; da história; da produção das identidades; e/ou, por que não, dos entrelugares. De certa maneira, são todos esses os espaços da cultura. Poderíamos questionar: que espaços, então, ocupar? Em que lugar firmar posição? Poderíamos responder: em todos quanto possível. É essa a essência do argumento e a proposta sobre a investida da formação inicial de professores(as).

Queremos ir além da formação para dizer que o(a) professor(a) deve aprender a ser professor(a) em espaços outros, que vão além da sala de aula das universidades/faculdades; da mesma forma que é preciso reivindicar uma posição política que dê conta de atuar em contextos fora da sala de aula da escola. A produção da identidade docente, sua representação e balizamentos se dão nas produções da cultura e essa deve ser encarada de frente em sua complexidade (GROSSBERG, 2015). Queremos dizer que a formação de professores(as) acontece e a identidade docente é também produzida em vários outros espaços que não os institucionais da educação e, nesse sentido, exigem atuação em diversas frentes de produção da realidade. Em outras palavras, necessita-se que estejamos dispostos(as) a ser e a formar professores(as) revolucionários, à maneira de Gilles Deleuze e Félix Guattari (2010) - ou seja, não se trata de revoluções institucionalizadas, poderosas, fascistas; mas de micro-revoluções, revoluções menores, por vias moleculares.

Hall (1995) propõe, então, que tenhamos, de alguma maneira, "a cultura em mãos" para poder muda-la. Talvez esse seja um projeto demasiadamente moderno, estafante e perigoso. A nós bastaria que convocássemos os(as) formadores(as) de professores(as) (consequentemente, os(as) próprios(as) professores(as)) à luta com suas condições mesmas de negociação com a realidade. O que convém dizer, dentro de nossa proposta, que todos os espaços, são espaços de atuação docente, porque são todos esses espaços que, culturalmente, 
produzem e traduzem o que é ser docente. Ou haverá alguém que possa dizer que, contemporaneamente, a internet é apenas reflexo de uma sociedade já constituída? Que se trata de uma "cibercultura", virtualmente isolada em algum espaço que pouco conversa com "a realidade"? Propomos uma complexificação nesse tipo de debate. O espaço virtual, por exemplo, não é "apenas" virtual, mas é também espaço de produção de realidade.

Por isso, propomos um trabalho ativo da formação inicial sobre a representação do(a) professor(a). Representação, claro, figura entre alguns dos conceitos centrais para essa discussão. Segundo Hall (2016), a representação na perspectiva da cultura é aquilo que participa ativamente na produção do significado. Ou seja, opõe-se tanto a um objeto de estudo "mentalista" que busca as "representações" de determinado sujeito; da mesma maneira escapa a uma representação idealista, de matriz platônica, que a entende enquanto cópia imperfeita do real (representação de algo que não está ali, por exemplo). Afirmamos o contrário: a representação é sempre produtiva. De diversas maneiras, a representação está intrinsecamente relacionada com o conceito de cultura - já que vimos que, chamamos pelo nome dessa última, justamente o compartilhamento desses significados. Atuar politicamente na representação da docência, é poder jogar com seus sentidos, suas marcas e atuação. É poder produzir novas identidades e, de várias maneiras, contrastar a concepção dos discursos que rebaixam a profissão a mero reprodutivismo ou ação partidária.

Romper com os espaços institucionalizados sobre a formação docente ou sobre o espaço de atuação promove uma nova lógica de pensamento e de aproximação com a(s) comunidade(s). Ora, o(a) próprio(a) professor(a) e a própria universidade/ faculdade passam a estar menos distantes do seu público alvo - o que faz com que esses também se identifiquem enquanto atuantes do contexto educacional que, novamente, ronda a cultura, não somente a escola (ou a universidade/faculdade). E esse é o ponto chave para a próxima proposição.

\subsection{Universidade e escola (precisam ser): lados da mesma moeda}

Foram mencionados os estudos de Zeichner (2013) e Nóvoa (2017) sobre a formação híbrida. É, certamente, uma concepção importante sobre a relação entre a formação de professores(as), a educação básica e a comunidade no entorno. Queremos, por outro lado, dentro da lógica múltipla, propor uma possibilidade para a formação inicial de professores(as) que se localiza, novamente, no espectro cultural: universidade/faculdade e escola como lados da mesma moeda. Queremos, no entanto, insistir na obviedade dessa afirmação. Não porque ela contenha algum tipo de argumentação irrefutável, mas porque não há, como afirmamos, "cultura formativa", "cultura escolar", "cultura comunitária", “cultura das políticas", dentre tantos outros possíveis. Todas essas instâncias pertencem à cultura de um modo geral e são, necessariamente, atravessadas em suas funcionalidades. Concordaríamos com a afirmação de que possuem suas particularidades, no entanto, pressupomos, o universo cultural não se dá em separado - debrucemo-nos sobre a questão.

Dissemos então que é a própria linguagem quem produz a realidade - e não a materialidade, típica conclusão que levaria alguns/algumas a dizerem que nos alocamos em alguma ala irrealista de pósmodernos. Produz a realidade porque é ela mesma quem institui o significado das coisas e, dessa forma, institui também nossas práticas em relação à materialidade e os contornos sobre como falamos, representamos, pensamos sobre algo, instituindo ciclos importantes de significações. Se isso enquanto processo compartilhado é o que Hall (1995) chama de cultura, seria equivocado pensar que cada espaço formativo (ou também atividade, seguimento corporal, produção artística, literária, etc.) institui, absolutamente, novos significados privados em relação a outro espaço do qual se toma como diferente. Assim, antes de mesmo de falar sobre as práticas que se atravessam, é necessário pensar que tudo faz parte do todo cultural - como propõe Deleuze (2018) nada existe fora do todo; assim como não existe o todo.

Poderíamos nos apropriar dessa afirmação de maneira bastante específica sobre o olhar cultural. Não existe atomicidade, pois não há nada fora do todo. Por outro lado, não existe um todo unificado, pronto a ser examinado e quantificado; resta-nos, na verdade, aquilo que se tenta, há muito (função especialmente escolar), reprimir: a multiplicidade das significações. Dessa forma poderíamos afirmar que comunidade, escola e formação inicial participam do todo; mas não formam um todo unificado, não são um todo, porque $o$ todo não existe - o que fecha 
nossa argumentação sobre não serem esses locais, lugares isolados que necessitam de aproximação.

Por outro lado, e aqui adentramos no segundo momento da proposta, isso que acabamos de afirmar abriria uma possibilidade de interpretação: cada local, enquanto espaço singular do todo, possui, então, especificidades de práticas e, por isso, realidades específicas. Concordaríamos. E é dessa forma que reclamamos uma aproximação - cultural, então, sobretudo.

A escola não pode ser um espaço estranho para os(as) discentes ou para os(as) formados(as). Seus sentidos precisam ser compartilhados nas universidades/faculdades, assim como a realidade das universidades/faculdades precisa estar presente no espaço escolar - em outras palavras, necessitamos de culturas que produza sentidos menos distanciados entre formação e educação básica justamente porque não se aprende a dar aula na universidade/ faculdade, mas compartilhando daquilo mesmo que se encontra em todos os espaços das escolas. Aqui se faz uma relação especificamente importante com a terceira proposta quando se diz que não há resultado essencialmente seguro a se pautar; ou espaço e momento específico em que ocorra a formação. Ninguém ensina a dar aula, esse é um movimento complexo de tradução das múltiplas formações do próprio sujeito-professor que independe (pelo menos em parte) de qualquer prova, trabalho ou conteúdo magistralmente criados e aplicados; assim como é mais importante, ao nosso ver, compartilhar dos significados escolares do que horas e horas de formação em espaço onde não acontece o objeto daquilo mesmo que se deve aprender.

Marca-se, com isso, novamente a posição docente. A docência está na formação inicial e nas escolas mas também nas políticas públicas, na comunidade e em diversos outros espaços. Está lá porque são todos esses lugares que constituem sua identidade e que formam para além da formação. Educação básica e formação inicial, compartilhando, mais ainda, realidades, diferenciando, funcionando a partir de diversas lógicas de conhecimento, sociedade e comunicação. Não pela possibilidade de sintetizar, unificar e tornar fundamental; mas justamente porque devemos, afirmando o abismo de possibilidades, perguntar: o que pode a hibridez da formação inicial e da educação básica?

\section{Considerações finais}

Vemos, então, baseados em Stuart Hall, que uma proposta cultural necessita, particularmente, de um olhar conjuntural. Por qualquer proposta que iniciássemos, poderíamos articular seus efeitos e modos de atuação - por exemplo quando nos convencemos de que a profissão docente é amplamente política; e, assim, que sua história demonstra não uma continuidade descompromissada, mas disputas e jogos de força que transcendem um local comum; da mesma forma que, enquanto postura ética, o pensamento político-histórico, por não se desenvolver em espaço restrito, ultrapassa a própria formação enquanto local fundamental da formação e compreende que o processo formativo não é delimitável; que, com isso, podemos questionar continuamente a identidade docente para que possa firmar posições outras, da mesma maneira que poderá, então, enquanto política, histórica e culturalmente orientada, resistir às investidas de representações maliciosas; para que isso ocorra de maneira ampla, precisamos formar professores(as) que ocupem os mais variados espaços, pois, além de atitude política da profissão, reconhece os diferentes locais de formação, de atuação e de negociação da realidade; por fim, daquilo que foi abordado, não poderá a formação inicial "superar-se" sem que aproximemos seus significados, dos significados compartilhados pelas mais diversas organizações escolares - dito de outra maneira, sem que hibridizemos, ainda mais, a cultura.

Entendemos que um limite importante que o artigo apresenta é em relação ao não-anúncio de maneiras, possibilidades e aplicabilidades. Por outro lado, essa é uma via de mão dupla. Porque é também, menos um limite, e mais uma opção teórica. Se aquilo que quisemos enfatizar ficou claro, é possível que pairassem dúvidas sobre nossos intentos de cristalização dos significados. Ora, apostar na multiplicidade é apostar menos na solução e mais no problema. É também, de certa forma, um reforço daquilo que vínhamos afirmando: se existem práticas culturais compartilhadas, mas não por isso menos singulares, traduzidas de maneiras diversas, por diversas realidades, talvez, pouco úteis fossem nossas concepções de atuação - mais importante é o benefício da possibilidade de novas conexões do pensamento; mais belo é o "sim" de Zaratustra (personagem conceitual nietzschiano) a todo o acaso. 
Sigamos atuando em favor de novas possibilidades de identidade docente; da mesma maneira que por novas formas de ação em sala de aula; assim como por novas formas de representação e de posicionamento político (e, claro, também em relação às políticas públicas). Que possamos propor e pensar o campo a partir de nossas próprias traduções da linguagem, do contexto cultural em que atuamos - e se isso for reinventar a roda, quão belo torna-se o movimento inventivo! Quem dirá que há aí menos virtude? Nossa luta é sim identitária; por outro lado, é, da mesma maneira, singular. Eis nossas propostas.

\section{Referências}

DELEUZE, G. Nietzsche e a filosofia. São Paulo: n-1 edições, 2018.

DELEUZE, G.; GUATTARI, F. O anti-Édipo: capitalismo e esquizofrenia 1. São Paulo: Ed. 34, 2010.

FOUCAULT, M. A arqueologia do saber. 7. ed. Rio de Janeiro: Forense Universitária, 2008.

GARCIA CANCLÍNI, N. Culturas híbridas: estratégias para entrar e sair da modernidade. 4. ed. 8 Reimp. São Paulo: Editora da Universidade de São Paulo, 2019.

GATTI, B. A.; BARRETO, E. S. de S.; ANDRÉ, M. E. D. de; ALMEIDA, P. C. A. de. Professores do Brasil: novos cenários de formação. Brasília: UNESCO, 2019.

GROSSBERG, L. Lutando com Anjos: os estudos culturais em tempos sombrios. MATRIZes, São Paulo, v. 9, no 2, p. 13-46, jul./dez. 2015.

GUATTARI, F.; ROLNIK, S. Cultura: um conceito reacionário? In: GUATARRI, F.; ROLNIK, S. Micropolítica: cartografias do desejo. Petrópolis: Editora Vozes, 2010.

${ }^{i}$ Utilizaremos "campo" em diferentes momentos neste artigo como uma forma abreviada para "campo de conhecimento". Ao falar sobre o "campo da formação de professores(as)" assumimos que existe uma produção teórica já bastante consolidada que, de certa forma, fala pela área. Autores(as) como Kenneth Zeichner, António Nóvoa, Bernardete Gatti, Marli André, são nomes importantes e inspirações diretas para a produção deste artigo.

ii A atomização cultural é um conceito importante que merece destaque. O disparador do pensamento é um texto intitulado "Cultura: um conceito reacionário?", escrito por Felix Guattari e organizado em livro por Suely Rolnik. No
HALL, S. A centralidade da cultura: notas sobre as revoluções culturais do nosso tempo. Educação \& Realidade, Porto Alegre, v. 22, n. 2, p. 15-46, jul./ dez. 1997.

HALL, S. A identidade cultural na pós modernidade. Rio de Janeiro: DP\&A, 2006.

HALL, S. Quem precisa de identidade? In: SILVA, T. T. Identidade e diferença: a perspectiva dos Estudos Culturais. 15 ed. Petrópolis, RJ: Vozes, 2014.

MACEDO, E. Currículo como espaço Currículo como espaço-tempo de fronteira cultural. Revista Brasileira de Educação, v. 11, n. 32, p. 285-372, maio/ago. 2006.

NÓVOA, A. Firmar a posição como professor, afirmar a profissão docente. Cadernos de Pesquisa, v.47, n.166, p.1106-1133, out./dez. 2017.

SCHÉRER, R. Aprender com Deleuze. Educação e Sociedade, Campinas, vol. 26, n. 93, p. 1183-1194, Set./Dez. 2005.

SILVA, T. T. A produção social da identidade e da diferença. In: SILVA, T. T. Identidade e diferença: a perspectiva dos Estudos Culturais. 15. ed. Petrópolis, RJ: Vozes, 2014.

SILVA, T. T. Documentos de identidade: uma introdução às teorias do currículo. Belo Horizonte: Autêntica, 2017.

WOODWARD, K. Identidade e diferença: uma introdução teórica e conceitual. In: SILVA, T. T. Identidade e diferença: a perspectiva dos Estudos Culturais. 15. ed. Petrópolis, RJ: Vozes, 2014.

ZEICHNER, K. Um futuro possível para a formação de professores nos Estados Unidos. In: Políticas de formação de professores nos Estados Unidos: como e porque elas afetam vários países do mundo. Belo Horizonte: Autêntica Editora, 2013.

texto, o filósofo-psicanalista francês expõe, logo no início, que parte da sua crítica ao conceito de cultura advém da empregabilidade de uma característica, aparentemente, autônoma: "A cultura enquanto esfera autônoma só existe a nível dos mercados de poder, dos mercados econômicos, e não a nível de produção, da criação e do consumo real" (GUATTARI; ROLNIK, 2010, p. 15). Nesse sentido, chamamos de atomização aquilo que é retirado de suas relações, de suas composições e hibridações, para ser objeto de algo. Somos levados a pensar em, pelo menos, uma impossibilidade fundamental: conceber a formação por ela mesma e dessa forma atuar culturalmente (e unicamente) 
em algo como "uma cultura formativa" ignorando seu caráter híbrido e disputável. A isso entenderemos por atomização da cultura.

iii Far-se-ia necessário um aprofundamento bastante compromissado em relação à diferenciação entre "identificação" e "desejo" - não é, certamente, nosso objetivo nesta oportunidade. Estaremos satisfeitos em dizer que Hall (2014) chama de identificação o processo de apego a uma posição de sujeito que ele busca resolver e interpretar através do desejo psicanalítico, baseado em Freud - nesse sentido, um desejo-falta, que deseja com o intuito de desejar menos. Por outro lado, em diversos momentos se faz presente uma articulação deleuze-guattariana nesse artigo, o que inviabiliza pensar o desejo dessa forma, já que em O Anti-Édipo (2010) os filósofos buscam fundamentar o desejo a partir de uma nova perspectiva - mais voltada ao pensamento nietzschiano, de desejo enquanto produção, intensidade, vontade, desejo de conexões. Seria, dessa forma, contraditório que nos valêssemos imensamente da "identificação" proposta por Stuart Hall. Acreditamos que ainda haja algumas relações a serem exploradas e melhor determinadas entre os pensadores (resguardadas as dificuldades de um movimento como esse). Por enquanto, é seguindo essa linha de pensamento que nos concentramos de maneira mais convicta na teorização das identidades sociais 